\title{
ON A STABLE COURSE
}

Dear Reader,

Whenever we think of a BMW motorbike, we automatically think of its typical Boxer engine. It has characterised the image of the brand for more than nine decades. And yet, just two years after its original Boxer motorcycle, the R 32 from 1923, BMW was already launching its singlecylinder range in the shape of the $\mathrm{R} 39$. It was some decades later, however, before BMW adopted a third engine concept by presenting the first four-cylinder inline engine of the K 100, in the early 1980s. It wasn't always received only with enthusiasm by some Boxer purists, like the most recent conversion to air/liquid cooling and vertical flow in the new Boxer engine. But today, inline and Boxer engines exist side-by-side in perfect harmony, and history has shown that BMW made the right decisions. The Munich-based manufacturer has gained new customers and is celebrating one sales record after another.

That is due not least to the numerous innovations that have always set BMW apart from the rest. The first hydraulically damped and adjustable telescopic fork went into series production as early as the 1930s, and ABS was launched at the end of the 1980s, followed shortly afterwards by the closed-loop three-way catalytic converter. 2012 saw the introduction of the first semi-active suspension, while the first premium electric Maxi-Scooter, the C evolution, was presented at this year's IAA in Frankfurt. These are just a few of the highlights.

BMW celebrated its 90th anniversary - for which I would also like to offer my congratulations - with special presents both for itself and for fans of the brand. The first is Concept Ninety, a concept bike developed in cooperation with bike specialist Roland Sands Design and inspired by the legendary R $90 \mathrm{~S}$; the second is the R nineT, a model to mark its 90th birthday and which is now going into series production. This naked bike with its classic style combines the design language of past epochs with cutting-edge state-of-the-art technology - a true eyecatcher. It can also be highly personalised due to the specially developed frame concept and extensive modifications to the electrics, which is another reason why the bike is likely to attract a huge fan following. The only possible downside to the $\mathrm{R}$ nine $\mathrm{T}$ is that it almost threatens to overshadow other models, such as the recently launched new R 1200 GS Adventure. A real luxury problem.

Financially sound, with technology at its usual high standard and with a wide, further diversifying model range supported by a faithful fan base, BMW Motorrad is ideally positioned for the years to come.

I hope you enjoy reading our interesting reports in this exciting special issue on 90 years of BMW Motorrad.

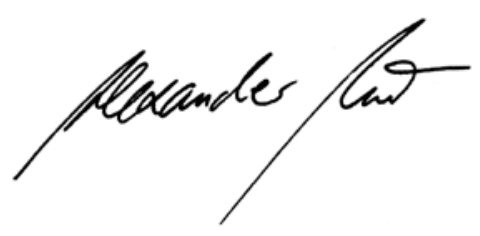

DR. ALEXANDER HEINTZEL, Editor in Chief Wiesbaden, 10 October 2013

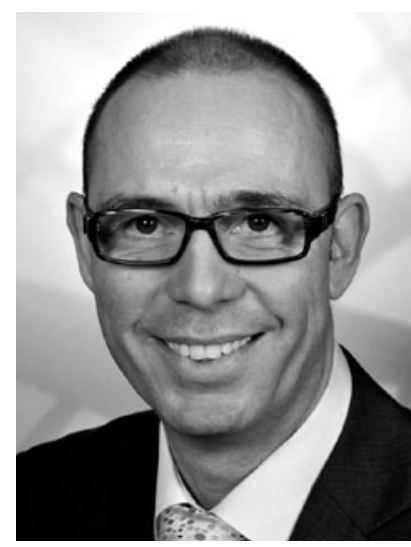

